\title{
The Design of Electro Cardiograph Signal Generator Using IC 14521 and IC 14017
}

\author{
Nur Hudha Wijaya ${ }^{1}$, Wahidun Arif Rijali ${ }^{2}$, Nishith Shahu ${ }^{3}$, Irfan Ahmad ${ }^{4}$, Rachmad Andri Atmoko \\ 1,2, 3, 4,5 Department of Electrical Engineering, Universitas Muhammadiyah Yogyakarta, Yogyakarta, Indonesia \\ Email: hudha@umy.ac.id, wahidun.arif@vokasi.umy.ac.id, nish2687@gmail.com, irfan.ahmed.mcse@gmail.com, \\ mokoraden@hotmail.com
}

\begin{abstract}
ECG or Electrocardiograph is a tool to find out the electrical activity of the heart in patients. Electrocardiogram (ECG) is a graphic result records electrical potential resulting from by heartbeat, (Mervin J. Goldman, 1990). ECG recording very useful to know present certain hypertrophy, arrhythmia, pericarditis, for example potassium electrolyte disturbances. Tool this be named generator signal ECG. Tool the generator signal ECG functioning for produce the signal Electric heart in adult patient sand to check ECG error or no. So that it can ease technical electro medic in maintenance medical equipment periodically. The tool utilizes IC 14521 as oscillator or signal generator and using IC 14017 as a shift register who has responsibility to remove from pin 1 to pin the other. The benefits of the ECG signal generating device so that technical electro medic easy and not difficult in check ECG without must using patients. So this tool as a form clone of the human heart. The tool such as a patient simulator. Based on the results of laboratory tests that have been done with the author concluded that, ECG signal generating device to function properly so that produce form of mock patient's heart signal that shown monitored oscilloscope in the wave form display $P, Q, R, S, T$.
\end{abstract}

Keywords—heart, Electro Cardiograph, shift register.

\section{INTRODUCTION}

Considering that heart disease has been ranked top of the diseases that are increasingly being found in Indonesian society, general practitioners as the main gateway and spearhead in serving the general public, holds the key to success in suppressing morbidity and mortality due to heart disease. For this reason, it is not excessive if all general practitioners should be able to use and utilize ECG properly.

In the hospital in practice it is inseparable from tools to check the electrical activity of the human heart, namely ECG (Electrocardiograph) which functions to determine the process of the patient's heart rate and activity value. The ECG tool is used repeatedly for several patients, so a patient simulator or ECG signal generator is needed to check the ECG device periodically and maintain the accuracy of the value generated and prevent errors, so it is safe when used by patients and users themselves.

The method used to determine damage to an ECG monitor patient is when the monitor is connected to an ECG signal generator, it can display PQRST frequency waves, or waves that produce an artificial human heart shape.
Whereas the existing ECG patient simulator uses 12 leads as its output. So that at the time of operation is more complicated. Then here the author makes an ECG signal divider using IC 14521 and IC 14017 as a supporting component.

Several previous researchers have conducted research on ECG. Microcontroller-based implant telemetry system for sympathetic nerve activity and ECG measurement was investigated by Enokawa et al [1]. The development of Qrs Detection Method for Direct Ambulatory Heart Monitor was investigated by So and Chan [2]. Real-time algorithms for portable recording of fetal and maternal heart rates were studied by Ahmed, Ali and Zahedi [3]. The development of a portable multi-functional patient monitor was investigated by Wong and Chan [4]. The concept for an event-induced electrocardiographic telemetry system using GSM for surveillance of cardiac patients was investigated by Gero von Wagner et al. [5]. Online QRS complex detection using wavelet filtering was investigated by Szilagyi et al [6]. The segmentation of heart rate variability under different physical activities was studied by Chan, Lin and Ko [7]. Wireless ECG Wireless Sensor for Wide Application in the Detection of Life Threatening Events was investigated by Welch, Guilak and Baker [8]. A Low Complexity EKG Imaging Algorithm for Real-Time Embedded Systems was investigated by [9]. Real-Time QRS Complex Detector Based on Discrete Wavelet Transformation and Adaptive Threshold as Independent Applications on ARM Microcontrollers was studied by [10].

Several previous researchers have conducted research to make a signal generator using a microcontroller and FPGA. Microcontroller Based Wireless ECG-Blood Telemonitor for Home Care was studied by Isais et al [11]. A microcontrollerbased portable electrocardiograph system was studied by Segura-Juarez, Cuesta-Frau and Samblas-Pena [12]. Multichannel telemetry system for monitoring physiological information of human gait: preliminary results studied by Formica, Tabernig and Escobar [13]. A PDA-based telemonitor electrocardiogram / blood pressure for telemedicine was studied by Bolanos et al [14]. Microcontroller based wireless recorders for biomedical signals were investigated by Chien et al [15]. The design of a microcontroller-based ECG signal generator using a microcontroller PWM output and experimental ECG data 
was investigated by Yener and Mutlu [16]. The design and implementation of a digital ambulatory ECG recorder based on multimediacard flash memory was investigated by Deniz and Yilmaz [17]. Low power Microcontroller based Wireless ECG Monitoring System design was studied by Fariborzi, Moghavvemi and Mehrkanoon [18]. The design of programmable electrocardiogram generator using microcontroller and CPLD technology was studied by Li et al [19]. The optimization of the Bluetooth wireless sensor system was studied by Lönnblad et al [20].

ECG signal generator tool with a simple circuit, using 3 LEDs or 3 electrode output cables that are connected to an ECG monitor or can be connected to an oscilloscope, but its value can only range between 60 to $120 \mathrm{BPM}$. The uncertainty value is only above the tolerance average which is not more than $0.3 \mathrm{BPM}$.

\section{METHOD}

In the block diagram of the ECG signal generator [21]-[23] shown in Figure 1, the voltage is as an input or input entered in the frequency processor consisting of IC 14521 and IC 14017. IC 14521 is an oscillator or signal generator, while IC 14017 is a shift register, moving from pin 1 to another. The frequency processor is powered by a 9volt battery. The output is in the form of PQRST ECG signal waves supported by an oscilloscope.

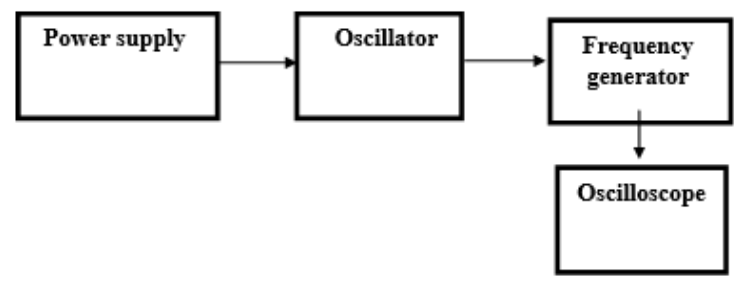

Fig. 1. System block diagram

\section{A. System work flow}

Figure 2 illustrates the ECG signal generator [24]-[26] flow chart that is the result of the process from beginning to end when the system is operating. Turning on the power press will turn on the indicator lights. Next, IC 14521 will generate a signal. Subsequently, the IC 14017 is entered as a trigger or refrigerate IC14521 to reading the resulted ECG signal on the monitor screen. This process occurs because the IC 14521 and IC 14017 are combined to create a PQRST stream.



\section{B. ECG signal generator}

A schematic sequence of ECG signal generator [27]-[30] devices used eagle application on a laptop. Figure 3 illustrates the schematic graph of the ECG signal generator device in the application.

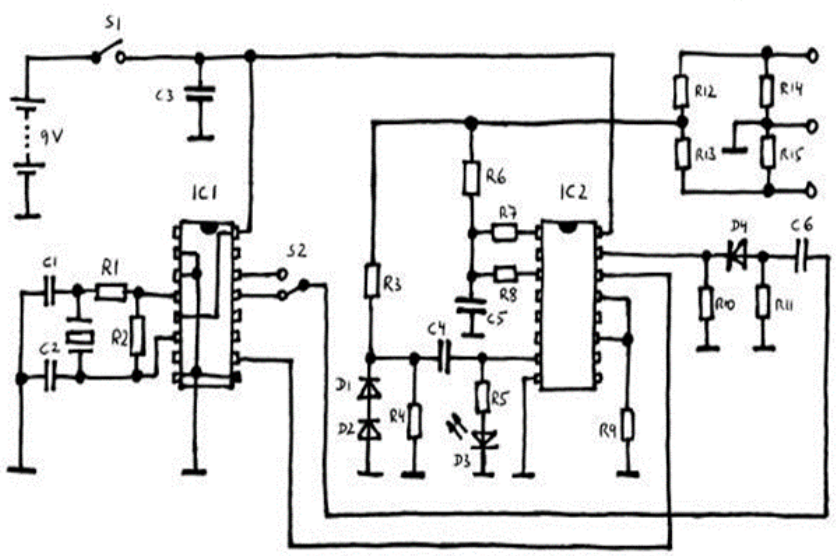

Fig. 3. ECG signal generator schematic

\section{Data analysis}

In the data analysis technique or ECG signal generator tool requires good accuracy, so there is no error in the tool, especially on some components.

\section{1) Component Check Analysis}

The first step when testing a tool is to use a multimeter or tester. Check one by one starting from the source using ohms $(\Omega)$. So the positive electrode cable on the tester is red and the black is black. Then the cable is connected to the positive and negative side sources, if the needle is moving the source is active and there is no damage.

The second step is checking the resistor components, so that it is easier to check the value of the resistor then it is recommended to use a digital tester so that the numbers can be seen. For example, if you check a resitor whose value is 100 kilo ohms $(\Omega)$ then the display on a digital tester will read the same. If the value on the digital tester is less or too more than the value of the resistor then the resistor is damaged. Then if you use a manual tester the sign is the needle is not moving. If the needle is moving, the resistor is still good.

The third step is checking on IC $14521 \mathrm{BP}$, which is connected to the 8 th leg on the positive electrode cable then the 16th leg is connected to the negative electrode cable. If the needle in the multitester does not move at all then the IC is damaged. Must replace the new IC. That's the way to check an electronic component that will be used in making tools.

\section{2) Tool Damage Analysis}

The next step is to check the overall tool by using an adapter or can use a power supply. So that it's easy to adjust the voltage needed.

Never happened when in the field while testing a device, there was a short circuit and an indicator light that should have been lit, in the end did not light up. Because there is a broken line. Then the IC caught fire and had to replace a new

Fig. 2. System work flow chart 
IC. Then what happens is that the device isn't functioning properly. The first step to analyzing a device is,

- It is possible that one of the components burned or overheated.

- The second is because when connecting positive and negative cables can be said to be wrong in the connection, so the device can not connect.

- Look closely at the PCB path could be due to a broken line.

- If there is a broken line then it can be connected to tenols.

- Then check using a multitester, check one by one on the components of the device, such as resistors, capacitors, ICs, and on the input and output that is from the source.

- If the resistor is broken then the needle on the multi manual tester will not move, if it moves then the resistor is still good.

- Then when checking the IC, which is checked is the input leg and output foot. If it does not work, the IC is certain to be damaged and cannot be used anymore.

\section{Device analysis result}

At the first time of testing the device, there was a shortcircuit or the tool did not function optimally. Then the way to analyze the tool is, by checking the tool as a whole starting from the source checked with a multimeter. If the needle in the multitester does not move, then it is certain that one of the lines is broken. The solution is to connect the disconnected path with tenols, so the path can function again. Next is checking on several components such as resistors, capacitors, ICs and diodes.

Based on the results of the analysis of the author when testing the device then there are ICs that do not work for sure the component is burned due to a short circuit. So the solution is before replacing the new IC, the author ensures that the IC checks the second time by checking one of the IC legs with a multimeter. Until in the end the results were zero. Then ascertained the IC is really damaged, then replace the new IC.

Based on the results of the analysis in the field the author also confirms other components such as resistors and capacitors. When checking the results are good and there are no problems. The results of the analysis when reviewing the layout path are also good, no problem.

At the second time of testing at the PKU Muhammadiyah Hospital in Yogyakarta City, accompanied by a field supervisor the results were good. Because at that time also had replaced the new IC components.

\section{IMPLEMENTATION}

Based on the results of the analysis in the field, the ECG signal generator is certain to be working optimally without any problems. With the help of an oscilloscope tool that functions to find out the frequency wave output or ECG signal. Based on the analysis results, the wave is good, by producing sine waves or waves in the form of a triangle that is in accordance with the material used. The results of the PQRST wave display can be seen in the image below, Figure 4.

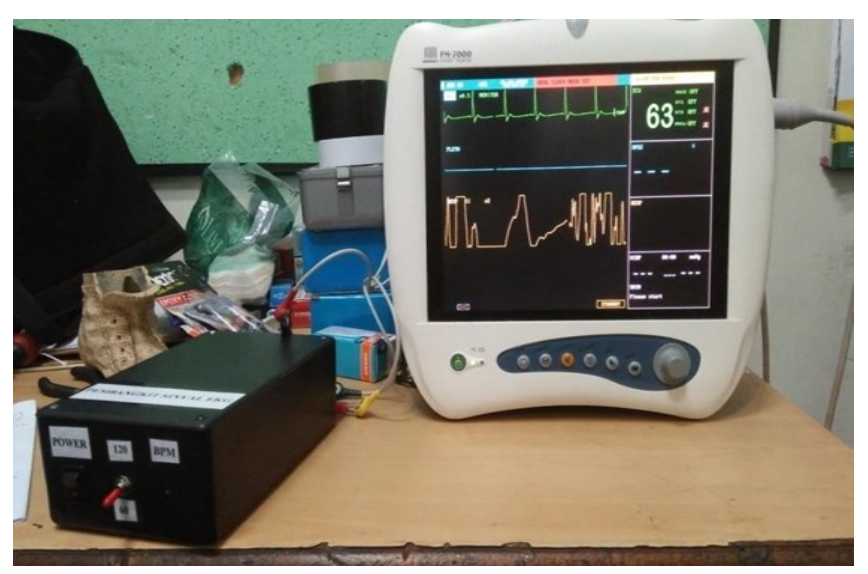

Fig. 4. System test result and PQRST wave

\section{A. How the tool works}

Before carrying out the checking process on the patient monitor, the first step is to connect the output cable to the oscilloscope or patient monitor then press the power button to the ON position then the battery will supply the voltage to the entire circuit in the module. When the switch is ON, the light will turn on then press the power button oscilloscope. The next step is set to channel 1, then the monitor screen will display PQRST waves. Define abbreviations and acronyms the first time they are used in the text, even after they have been defined in the abstract. Abbreviations such as IEEE, SI, MKS, CGS, SC, DC, and RMS do not have to be defined. Do not use abbreviations in the title or heads unless they are unavoidable.

\section{B. Test Results on ECG Signal Generator}

The material created by the author is an ECG signal generator that can produce human heart wave signals between 60 and 120 BPM. This tool can also be used to check ECG errors or not. So that the user of an ECG device can operate it safely. The use of the ECG signal generator is the same as that of an ordinary ECG simulator, but the device discussed here is even simplified to use 3 electrode cables connected to the ECG monitor or to the oscilloscope. when checking and maintaining ECG devices regularly. The ECG signal generator has several connected component functions

\section{CONCLUSION}

Test results at the PKU Muhammadiyah Hospital's electromedical laboratory showed that the ECG signal generator was working properly. The results of the laboratory tests showed normal PQRST waves displayed on the monitor screen. The device used 9volt IC HEF 14521 BP and IC HCF 4017 B batteries. IC 14521 was used to generate IC 4017 B cooled ECG signal waves. The designed generator had parameters between 60 and 120 BPM, but it showed uncertainty values between 63 and 127 BPM when tested. The system may be inferred to have a flaw in the number change stage. The device could also be used to test the erroneousness of an ECG display and to enable daily check by the electromedical technicians. The error rate was estimated based on the estimation checks. The error rate of 
the signal generator was $2 \%$. Because the error rate was $<5 \%$, the device was said to be worth using that showed the level of trust of more than $99 \%$, and the probability level (chance of error) was less than $3 \%$.

\section{REFERENCES}

[1] C. Enokawa, Y. Yonezawa, H. Maki, and M. Aritomo, "A microcontroller-based implantable telemetry system for sympathetic nerve activity and ECG measurement," in Proceedings of the 19th Annual International Conference of the IEEE Engineering in Medicine and Biology Society. "Magnificent Milestones and Emerging Opportunities in Medical Engineering" (Cat. No.97CH36136), 1997, vol. 5, no. C, pp. 2232-2234.

[2] H. H. So and K. L. Chan, "Development of Qrs Detection Method for Real-Time Ambulatory Cardiac Monitor," in Proceedings of the 19th Annual International Conference of the IEEE Engineering in Medicine and Biology Society. "Magnificent Milestones and Emerging Opportunities in Medical Engineering" (Cat. No.97CH36136), 1997, vol. 1, no. C, pp. 289-292.

[3] F. Ahmed, M. A. M. Ali, and E. Zahedi, "A real time algorithm for the portable recording of fetal and maternal heart rates," in 2000 TENCON Proceedings. Intelligent Systems and Technologies for the New Millennium (Cat. No.00CH37119), 2000, vol. 1, pp. 246251.

[4] C. Wong and K. L. Chan, "Development of a portable multifunctional patient monitor," in Proceedings of the 22nd Annual International Conference of the IEEE Engineering in Medicine and Biology Society (Cat. No.00CH37143), 2000, vol. 4, pp. 26112614.

[5] Gero von Wagner, S. Schubert, L. F. Ngambia, C. Morgenstern, and A. Bolz, "Concept for an event-triggered electrocardiographic telemetry-system using GSM for supervision of cardiac patients," in IEEE/AFCEA EUROCOMM 2000. Information Systems for Enhanced Public Safety and Security (Cat. No.00EX405), 2000, pp. 374-377.

[6] L. Szilagyi, Z. Benyo, S. M. Szilagyi, A. Szlavecz, and L. Nagy, "On-line QRS complex detection using wavelet filtering," in 2001 Conference Proceedings of the 23rd Annual International Conference of the IEEE Engineering in Medicine and Biology Society, 2001, vol. 2, pp. 1872-1874.

[7] H. L. Chan, C. H. Lin, and Y. L. Ko, "Segmentation of heart rate variability in different physical activities," in Computers in Cardiology, 2003, 2003, vol. 30, pp. 97-100.

[8] J. Welch, F. Guilak, and S. D. Baker, "A Wireless ECG Smart Sensor for Broad Application in Life Threatening Event Detection," in The 26th Annual International Conference of the IEEE Engineering in Medicine and Biology Society, 2004, vol. 4, pp. 3447-3449.

[9] J. M. Bote, J. Recas, F. Rincon, D. Atienza, and R. Hermida, “A Modular Low-Complexity ECG Delineation Algorithm for RealTime Embedded Systems," IEEE J. Biomed. Heal. Informatics, vol. 22, no. 2, pp. 429-441, Mar. 2018.

[10] V. H. Rodriguez, C. Medrano, and I. Plaza, "A Real-Time QRS Complex Detector Based on Discrete Wavelet Transform and Adaptive Threshold as Standalone Application on ARM Microcontrollers," in 2018 International Conference on Biomedical Engineering and Applications (ICBEA), 2018, pp. 1-6.

[11] R. Isais, K. Nguyen, G. Perez, R. Rubio, and H. Nazeran, "A lowcost microcontroller-based wireless ECG-blood pressure telemonitor for home care," in Proceedings of the 25th Annual International Conference of the IEEE Engineering in Medicine and Biology Society (IEEE Cat. No.03CH37439), 2003, vol. 4, pp. 3157-3160.

[12] J. J. Segura-Juarez, D. Cuesta-Frau, and L. Samblas-Pena, "A microcontroller-based portable electrocardiograph system," in 10th IEEE International Conference on Electronics, Circuits and Systems, 2003. ICECS 2003. Proceedings of the 2003, 2003, vol. 2, pp. 922-925.

[13] M. Formica, C. Tabernig, and S. Escobar, "A multichannel telemetry system for monitoring physiological information from the human gait: preliminary results," in Proceedings of the 25th Annual International Conference of the IEEE Engineering in Medicine and Biology Society (IEEE Cat. No.03CH37439), 2003, vol. 2, pp. 1799-1802.

[14] M. Bolanos, H. Nazeran, I. Gonzalez, R. Parra, and C. Martinez, "A PDA-based electrocardiogram/blood pressure telemonitor for telemedicine," in The 26th Annual International Conference of the IEEE Engineering in Medicine and Biology Society, 2004, vol. 3, pp. 2169-2172.

[15] C.-N. Chien, H.-W. Hsu, J.-K. Jang, C.-L. Rau, and F.-S. Jaw, "Microcontroller-based wireless recorder for biomedical signals," in 2005 IEEE Engineering in Medicine and Biology 27th Annual Conference, 2005, vol. 7 VOLS, pp. 5179-5181.

[16] S. C. Yener and R. Mutlu, "A microcontroller-based ECG signal generator design utilizing microcontroller PWM output and experimental ECG data," in 2018 Electric Electronics, Computer Science, Biomedical Engineerings' Meeting (EBBT), 2018, pp. 14.

[17] T. Deniz and A. Yilmaz, "Design and implementation of a digital ambulatory ECG recorder based on flash multimediacard memory," in 2003 46th Midwest Symposium on Circuits and Systems, 2006, vol. 1, pp. 368-371.

[18] H. Fariborzi, M. Moghavvemi, and S. Mehrkanoon, "Design of a Low-power Microcontroller-based Wireless ECG Monitoring System," in 2007 5th Student Conference on Research and Development, 2007, no. December, pp. 1-4.

[19] Y. Li, S. Wu, J. Li, Y. Bai, and S. Zhang, "The Development of Embedded EGG Recorder Based on ARM9," in 2007 IEEE/ICME International Conference on Complex Medical Engineering, 2007, pp. 230-233.

[20] J. Lönnblad, J. G. Castaño, M. Ekström, M. Lindén, and Y. Bäcklund, "Optimization of wireless bluetoothTM sensor systems," Annu. Int. Conf. IEEE Eng. Med. Biol. - Proc., vol. 26 III, pp. 21332136, 2004.

[21] Y. Ren et al., "System of Multi-parameter for Anaesthesia depth monitor," in International Symposium on Bioelectronics and Bioinformations 2011, 2011, pp. 45-48.

[22] A. Sobrinho, P. Cunha, L. D. Da Silva, A. Perkusich, T. Cordeiro, and J. Rego, "A simulation approach to certify electrocardiography devices," 2015 17th Int. Conf. E-Health Networking, Appl. Serv. Heal. 2015, pp. 86-90, 2015.

[23] M. Sayahkarajy and E. Supriyanto, "Design of a temporay external artificial pacemaker simulator," in 2017 International Conference on Robotics, Automation and Sciences (ICORAS), 2017, pp. 1-8.

[24] L. Yang, "Development and application of ECG bedside monitor," in 2009 9th International Conference on Electronic Measurement \& Instruments, 2009, pp. 4-390-4-394.

[25] J. E. Gaxiola-Sosa, N. Mohsin, A. J. Palliyali, R. Tafreshi, and K. Entesari, "A portable 12-lead ECG wireless medical system for continuous cardiac-activity monitoring," in 2nd Middle East Conference on Biomedical Engineering, 2014, pp. 123-126.

[26] H. Vashi, G. T. Haldankar, and Y. S. Rao, "Detection of Atrioventricular Node and Its Parameters Using ECG," in 2012 Fourth International Conference on Computational Intelligence and Communication Networks, 2012, pp. 295-299.

[27] K. K. M. Rahman, M. M. Subashini, M. Nasor, and A. Tawfik, "Development of bio-shields for Arduino Uno," in 2018 Advances in Science and Engineering Technology International Conferences (ASET), 2018, pp. 1-5.

[28] A. Vehkaoja, T. Salpavaara, J. Verho, and J. Lekkala, "EMFi material as wearable heart rate sensor for night time recordings," in 2010 IEEE Sensors, 2010, pp. 145-149.

[29] I. Orha and S. Oniga, "Automated system for evaluating health status," in 2013 IEEE 19th International Symposium for Design and Technology in Electronic Packaging (SIITME), 2013, pp. 219-222.

[30] Vidhya V and D. Unnikrishnan, "Synthetic ECG and PPG signal generation using pulse shaping technique," in 2015 Annual IEEE India Conference (INDICON), 2015, pp. 1-6. 